\title{
EL DERECHO CONSUETUDINARIO EN CASTILLA. UNA CRÍTICA A LA MATRIZ ROMÁNTICA DE LAS INTERPRETACIONES SOBRE LA COSTUMBRE
}

por

PAOLA Miceli

Universidad Nacional de General Sarmiento (Argentina)

RESUMEN: Este artículo tiene como objetivo revisar la idea, fuertemente arraigada en la tradición de la bistoria del derecho español, según la cual la no aplicación del "Liber» después del siglo $X$ en Castilla permitió el desarrollo de un derecho popular consuetudinario. La bipótesis que se desarrolla es que en las interpretaciones acerca del derecho castellano altomedieval existe una sobreinterpretación del fenómeno consuetudinario anclado en una mirada romántica de la costumbre, mirada que considera al derecho consuetudinario como espontáneo, inmanente a las prácticas sociales, emergiendo de los comportamientos bumanos. Se analiza la documentación foral entre los siglos X-XIV con el objeto de demostrar que la aparición del concepto «consuetudo» en los fueros castellanos, lejos de vincularse con un derecho de raíces populares y espontáneas guarda una estrecha relación con el trabajo de los romanistas y canonistas sobre el derecho romano.

Palabras Clave: España. Castilla. Edad Media. Costumbre. Derecho romano.

ABSTRACT: The subject of this article is to reconsider the idea, strongly rooted in the tradition of the history of Spanish law, according to which the development of customary law in tenth-century Castile was a consequence of the "Liber». It is proposed bere that there exists an romanticised view of customary law in interpretations of the early medieval Castilian law based on a romantic view of the custom. This view presumes the customary law to be spontaneous, immanent in social practices, emerging naturally from buman behaviour. This article analyses the evidence of the Castilian «fueros» between tenth and fourteenth centuries in order to demonstrate that, far from being linked with popular and spontaneous origins, the appearance of customary law was closely related to the work of the Roman and canon lawyers.

KeY wORDS: Spain. Castile. Middle Ages. Custom. Roman Law. 
Uno de los tópicos de la historia del derecho español sostiene que tras la caída de la monarquía visigoda y el derecho del Liber, la población goda habría empezado a aplicar un derecho popular consuetudinario, que luego se fijaría en fueros y cartas pueblas. Según este hecho, nos enfrentaríamos a un derecho germánico altomedieval de raíz consuetudinaria.

La existencia de este derecho germánico fue desigual en las distintas regiones de España. En Asturias y León el Liber se restableció entre los siglos IX y $\mathrm{X}$. Por el contrario, las zonas de Castilla, Navarra y Aragón seguirían desconociendo durante algunos siglos el texto visigótico, haciendo posible la hegemonía de la costumbre'.

El carácter de este derecho altomedieval español provocó numerosos debates historiográficos. Una buena parte de las discusiones giraron en torno de la pertinencia o no de hablar de un derecho germánico como cuerpo homogéneo, distinto y enfrentado al derecho romano ${ }^{2}$. Como es sabido, García Gallo planteó que el derecho germánico como construcción doctrinal no tuvo vigencia en ningún momento histórico ni en ningún territorio concreto, sino que fue

«una abstracción teórica de laboratorio elaborada por los estudiosos contemporáneos sobre principios extraídos de los diferentes derechos de los distintos pueblos de raza germánica» ${ }^{3}$.

Según Gallo, los pueblos del norte de España deficientemente romanizados conservaron sus costumbres prerromanas y las llevaron consigo en el momento que repoblaron la meseta. Esto significa, según Gallo, que el derecho medieval fue resultado de una mezcla de distintos ordenamientos jurídicos: prerromano, romano, visigodo 4 .

\footnotetext{
$A H D E=$ Anuario de Historia del Derecho Español (Madrid).

Droits $=$ Droits. Revue Française de Théorie Juridique (París).

Glossae $=$ Glossae. Revista de Historia del Derecho Europeo (Murcia).

$R S J B=$ Recueil de la Societé Jean Bodin (Bruselas).

1 En regiones tales como Navarra, Castilla, Asturias y los valles del Pirineo, el Libro dejó de aplicarse. Cf. García GaLlo, A.: «Aportación al estudio de los fueros» en $A H D E 26$ (1956) pp. 387-446/ 391: «Sólo al cabo de un siglo Alfonso II (792-842) lo restableció en Asturias, y a principios de siglo $\mathrm{X}$ los mozárabes que procedentes de la España musulmana se establecieron en León contribuyeron a que en esta región se difundiese la ley gótica».

2 Algunos de los más reconocidos defensores de la tesis germanista han sido: Ficker, Hinojosa, García de Valdeavellano. La serie de objeciones que se han formulado a esta tesis podrían resumirse en dos: por un lado, hay quienes sostienen que no existe un derecho germánico como un cuerpo de doctrinas estructurado, en esta línea podemos ubicar a A. García y Gallo; por otro lado, un grupo de historiadores romanistas, consideran que el derecho altomedieval es una prolongación de la tradición jurídica romano-vulgar que tras la caída del Imperio pervivió en la monarquía visigoda. En esta línea se encuentran A. Otero, A. Iglesia, C. Petit.

3 Gacto Fernández, E.: Temas de historia del derecho. Derecho medieval, Sevilla, 1979, p. 37.

4 García Gallo, A.: Curso de bistoria del derecho español, Madrid, 1947, p. 222.
} 
Ahora bien si la existencia de un derecho germánico está hoy en día muy cuestionada, lo que no ha sido puesto en duda es la existencia de derecho consuetudinario en Castilla durante los primeros siglos medievales. Este artículo tiene como objetivo revisar la idea, fuertemente arraigada en la tradición de la historia del derecho español, según la cual la no aplicación del Liber después del siglo $\mathrm{X}$ en Castilla permitió el desarrollo de un derecho popular consuetudinario. Nuestra hipótesis de trabajo es que en las interpretaciones acerca del derecho castellano altomedieval existe una sobreinterpretación del fenómeno consuetudinario anclado en una mirada romántica de la costumbre. ¿A qué llamamos mirada romántica? A aquellos trabajos que piensan al derecho como espontáneo, inmanente a las prácticas sociales, emergiendo de los comportamientos de los hombres y que, por tanto, conciben a la costumbre «surgida en el suelo de los ancestros» ${ }^{5}$. Estos trabajos no provienen necesariamente de la misma disciplina sino que pueden originarse en la historia, la sociología, la historia del derecho, etc. Uno de los ejemplos más representativos de esta forma de pensar el derecho consuetudinario es Paolo Grossi para quien el derecho se encuentra en estado primario arraigado en las cosas y luego se eleva hacia la doctrina:

«[el derecho consuetudinario es] por su propia naturaleza la normativa de la cosa, es decir, se deriva de la cosa: hecho natural entre los hechos naturales, es en lo real donde se alimenta, desde lo real puede proyectarse hacia lo alto y convertirse en norma de una comunidad humana, pero su origen permanece factual, particular; alcanza a las estructuras, nace desde abajo» ${ }^{6}$.

Pensado como escencia de la cosa o de los hombres no existe momento histórico en el que la costumbre no haya existido.

Nos interesa sortear este prejuicio y trabajar sobre la dimensión jurídica de la costumbre. Consideramos que el derecho consuetudinario es producto de una voluntad jurídica más que expresión de una voluntad popular. El derecho consuetudinario, tomando palabras de Troper, es creado «non pas par suite de quelque mystérieuse transformation du fait en droit, mais simplement par l'operation du juge qui a interprété le fait ${ }^{7}$. De esta forma el pasaje de la regula-

5 Yan Thomas plantea que existe toda una mitología que data del último siglo (más particularmente del romanticismo alemán) que concibe al derecho de esta forma y que dio origen a una serie de mitos entre los que se encuentra esta idea de la costumbre surgida de las prácticas ancestrales. Cf. Thomas, Y.: Los articificios de las instituciones, Buenos Aires, 1999, pp. 9-12.

6 Grossi, P.: El orden jurídico medieval, Madrid, 1996, p. 109.

7 TROPER, M.: «Du fondement de la coutume à la coutume comme fondement» en Droits 3 (1986) pp. 11-24/ 21 (número especial sobre La coutume). Dentro de esta misma corriente se presentan discusiones acerca de cuál es en última instancia la voluntad que decide. Para algunos se trata de la voluntad del legislador. Para otros, entre los cuales se encuentra Kelsen, la costumbre es resultado de la voluntad del juez. Como sostiene Troper (ibidem, p. 21), para Kelsen «le juge crée la norme coutumière comme il crée la norme législative». Véase asimismo TROPER, M.: «Kelsen, la théorie de l'interpretation et la structure de l'ordre juridique», en Revue Internationale de Philosophie (1981) pp. 518-529. 
ridad del hecho al derecho consuetudinario se operaría no por desarrollo natural sino por la intervención de una voluntad subjetiva, la del juez, en tanto agente del sistema jurídico oficial que «métamorphose les simples usages... en véritables coutumes juridiques, sanctionnées par l'ordre permanent d'exécution» ${ }^{8}$.

El juez no opera aquí como individuo particular sino como representante de una voluntad: las reglas consuetudinarias son instituidas por órganos que otorgan a ciertas prácticas significación de normas. Es decir, existe una regla que dice que la regularidad jurídica existe; el paso del hecho al derecho se opera entonces por una regla interior al discurso jurídico. Sin regla jurídica que establezca que un tipo de regularidad es norma, la costumbre desde el punto de vista jurídico no existe.

La aparición histórica de esta regla está ligada a la tradición romanista. En el derecho romano la costumbre cumplía un papel activo. Sin embargo, en ninguna parte del Corpus Iuris se hace referencia a la costumbre como ius. Como sostiene Gouron, «elle a été imaginée par les glossateurs au moment où ils elaboraient une théorie de la coutume»9. La costumbre como derecho es por ende una invención de los juristas medievales en torno al siglo $\mathrm{XII}^{10}$.

Si como acabamos de postular, para que se instituya la regla jurídica que establece que una regularidad jurídica existe es necesaria la influencia del derecho romano, ecómo es posible que los historiadores encuentren hegemonía del derecho consuetudinario antes de la formulación de la regla que dice que la costumbre es derecho? El siguiente apartado intenta ser una respuesta a esta enmarañada pregunta.

\section{LA MATRIZ ROMÁNTICA DE LAS INTERPRETACIONES SOBRE EL DERECHO CON- SUETUDINARIO}

Un análisis de la documentación foral castellana correspondiente a los siglos X, XI y XII nos enfrenta con el siguiente problema: desde la historiografía se sostiene la existencia de derecho consuetudinario a lo largo de estos siglos, pero en la documentación no encontramos la presencia del término consuetudo o de algún otro concepto (usus o mos) que se relacione con él ${ }^{11}$. A partir de la lectura de los privilegios y fueros breves concedidos por reyes y condes a lo largo

8 LAMBeRT, E.: Études de droit commun législatif et de droit civil comparé, París, 1903, p. 802; citado por COMBACAU, J.: «Ouverture: de la régularité à l'régle» en Droits 3 (1986) pp. 3-10/ 4.

9 Gouron, A.: "Sur les origines de léxpression "droit coutumier"» en Glossae 1 (1988) pp. 179-188/ 179.

10 Ibidem. Ver MAYALI, L.: «La coutume dans la doctrine romaniste au Moyen Âge» en RSJB 52 (1990) pp. 11-31 (número especial sobre La coutume).

11 Este mismo punto de partida es tomado por Gouron, A.: "Aurore de la coutume» en Recueil de Mémoires et Travaux. Société d'Histoire de Droit et des Institutions des Anciens Pays de Droit Écrit 14 (1988) pp. 181-187/ 181 (= Droit et coutume en France aux XIle et XIIle siècles, Norfolk, 1993).

Hispania, LXIII/1, núm. 213 (2003) 9-28 
de los siglos $\mathrm{X}$ y $\mathrm{XI}^{12}$ podemos señalar que no existe ninguna mención a consuetudo. Tampoco hallamos algún concepto que resuma la idea de derecho no escrito obligatorio practicado por la mayor parte de la comunidad ${ }^{13}$. En los fueros que se otorgan posteriormente durante los siglos XI y XII se repite esta característica: la consuetudo no aparece, ni tampoco otras formas que puedan entenderse como sinónimos, ya sea usus o mos.

¿Significa esto que durante la alta edad media castellana no existía regularidad ni normatividad alguna entre los hombres medievales? De ninguna manera, lo que debemos tener presente en este punto es la siguiente distinción: la regularidad, por un lado, y la costumbre como derecho, por otro, son dos cosas radicalmente diferentes. La primera hace referencia a la permanencia de hábitos, prácticas, sin que esta reiteración sea generadora de derecho. El ius consuetudinarium, en cambio, supone que hay determinadas regularidades que al cumplir las condiciones establecidas desde el discurso jurídico se vuelven costumbre con capacidad de generar derecho. Por lo tanto, los hechos no pueden crear derecho si no hay una regla jurídica que ordene las prácticas según su conformidad.

La cuestión de los hábitos que se reiteran o la normatividad en estado práctico es del orden de lo social y no del orden de lo jurídico, y, por lo tanto, no es el problema que nos interesa abordar. Nuestro interés radica en explicar por qué si los documentos de los que disponemos no utilizan los conceptos consuetudo, usus y mos, y aún menos derecho consuetudinario, los historiadores han visto allí un derecho originado en la costumbre.

La historiografía ligada al derecho medieval habla, como ya señalamos, de un predominio del derecho consuetudinario en algunas regiones de la península. Según una formulación,

«Castilla, Navarra y Aragón siguieron desconociendo el Liber. En todas estas regiones -en unas hasta el siglo IX o X; en otras hasta el XIII o el XIV- la costumbre fue la única fuente del Derecho» 14 .

12 Muñoz y Romero, T.: Colección de fueros municipales y cartas pueblas de Castilla, León, Corona de Aragón y Navarra, tomo I, Madrid, 1847, pp. 36-42. Otorgados por García Fernández: Privilegios del Monasterio de Santa María de Remondo, en marzo de 969; Fuero de Castrojeriz, en marzo de 974 (recogido en una confirmación posterior de Fernando III); Escritura de Fundación del Monasterio de San Cosme y San Damián de Covarrubias, en diciembre de 978. Otorgados por Don Sancho: Donación al Monasterio de San Salvador de Oña, en 1011; Fuero de Nave de Albura, en 1012. Hemos analizado también otros fueros como el de Alcalá de Henares, el de Medinaceli, etc.

13 El caso del fuero latino de Sepúlveda puede parecer una excepción respecto de esta situación. Sin embargo, no olvidemos que el texto del fuero se conoce a través de una copia de la confirmación hecha por Alfonso VII en la segunda mitad del siglo XII. Por lo tanto, es esta fecha la que debemos tener en cuenta. Véase SÁEZ, E.: Los fueros de Sepúlveda, Segovia, 1953, pp. 348 ss.

14 García Gallo, A. «Aportación al estudio de los fueros» en AHDE 26 (1956) pp. 387-446/ 392 , n. 25 .

Hispania, LXIII/1, núm. 213 (2003) 9-28 
De acuerdo con otra,

«el derecho medieval castellano, cuyo objetivo primordial es el mantenimiento de la paz entre los miembros de la comunidad a la que rige... es un derecho esencialmente consuetudinario...»15.

Y así, podríamos seguir señalando otros muchos ejemplos en donde se desarrolla esta idea muy afianzada en la tradición de los historiadores del derecho ${ }^{16}$.

Sin embargo, analizando los documentos vemos que esta presencia incuestionable del derecho consuetudinario es una radical inexistencia: hasta el siglo XII o XIII, según la colección de fueros de Castilla que analizamos, no se hace mención alguna a costumbre ni a otro término factible de ser traducido como tal. La presencia de consuetudo, usus y mos recién se evidencia en los documentos avanzado el siglo XII.

¿Por qué según el pensamiento de estos autores aun estando ausente el derecho consuetudinario determina la situación? La respuesta hay que buscarla en los supuestos teóricos sobre los que se asientan tales argumentaciones. Partamos de una aseveraciọ́n de Galo Sánchez:

«Apoyándose en ocasiones en la costumbre del país o completándola, los jueces castellanos construyeron un nuevo derecho. Fijaron las normas jurídicas extrayendo de las borrosas reglas consuetudinarias los principios fundamentales cuando esto fue hacedero. Separaron lo jurídico de lo no jurídico; y con su personal criterio definieron, en resumen, el derecho castellano» 17.

Según esto, los jueces castellanos construyeron el derecho clarificando las borrosas reglas en estado práctico. La regla jurídica se encontraría latente en el mundo de lo social y sería el trabajo del jurista o juez el que la puliría y elevaría al rango de derecho. Sería necesaria la intervención del juez porque en la práctica lo jurídico y lo no jurídico se encontrarían mezclados. El juez tendría un papel central en la creación del derecho pero no porque, como planteábamos unas páginas más arriba, instituyera la costumbre a partir de una regla interior a lo jurídico, sino porque su tarea consistiría en descubrir lo jurídico en la dimensión de lo social.

El primer punto a tener en cuenta es el supuesto que se halla operando aquí: el derecho consuetudinario derivaría de los hechos. Así, desde lo factual, el derecho consuetudinario fluiría para convertirse en norma bajo la supervisión

15 PÉReZ-PRendes, J.M.: Curso de historia del derecho español, Madrid, 1989, p. 509.

16 BENEYTO, J.: «Para la clasificación de las fuentes del derecho medieval español» en $A H D E$ 31 (1961) pp. 259-268; GiberT, R.: «El derecho municipal de León y Castilla» en $A H D E 31$ (1961) pp. 695-753; SÁNCHEZ, G.: «Para la historia de la redacción del antiguo derecho territorial castellano» en $A H D E 6(1929)$ pp. 260-328; GACTO FERNÁNDEZ, E.: op. cit. (n. 3), p. 69.

17 SÁNCHEZ, G.: op. cit., p. 263. 
del especialista. La costumbre se encontraría ya arraigada en los actos de los hombres y sería el jurista el encargado de descubrirla. En otro pasaje Galo Sánchez, refiriéndose a la constitución de los derechos territoriales en la vieja Castilla, pone de relieve cómo se constatarían en dicho proceso dos momentos diferentes pero complementarios en la práctica jurídica: en primer lugar, el redactor fijaría por escrito una norma latente en la vida consuetudinaria; en segundo lugar, la convertiría en norma abstracta ${ }^{18}$. La práctica jurídica funcionaría como reflejo de las prácticas sociales ${ }^{19}$. El derecho consuetudinario nacería así debido a la metamorfosis del hecho en derecho.

Una derivación de esta analítica supone considerar a la costumbre naturaleza arraigada en el comportamiento humano. De Cicerón a Montaigne la costumbre fue considerada la segunda naturaleza del hombre, es decir, hábito encarnado de forma tal que se ha perdido el registro de su aprendizaje ${ }^{20}$. En tanto ligada a la naturaleza, la costumbre aparecería como fundamento primero, materia prima pura sobre la que se montarían externamente las transformaciones socioculturales. Es por lo tanto obvio, a partir de este razonamiento, que la costumbre se encontraría en una dimensión distinta, y hasta opuesta quizás, a la ley que no participaría del orden de lo ya dado sino del de lo creado. De esta forma resulta imposible pensar alguna situación histórica en la que la costumbre no se encuentre presente: mientras existan hombres existirá la costumbre.

Un último punto consiste en percibir la matriz metafísica que recorre estas interpretaciones. En primer lugar, ellas parten de una concepción general, ahistórica, de la noción de costumbre capaz de operar la representación de un conjunto de prácticas tradicionales, regulares, etc. En segundo lugar, establecen como existente aquello que la noción de costumbre representa, es decir, lo representado que la definición ahistórica de la noción en cuestión viene a significar. De esta forma logran encontrar un derecho consuetudinario antes de que exista como concepto.

En definitiva, la articulación entre estos supuestos que operan en estas posiciones implica que el derecho sería un discurso que representaría la realidad: el derecho diría en un lenguaje "culto" lo que ya estaría vigente, aunque toscamente, en el mundo real. La costumbre sería una forma sencilla, rústica y popular de ordenamiento de la vida que se encontraría funcionando en el mundo de las prácticas hasta la llegada de los juristas encargados de poner por escrito este derecho latente. Pero la escritura sería un reflejo de lo que ya existiría en estado tosco y rústico: el ius consuetudinarium sería reflejo del derecho popular latente en las prácticas de los hombres. El siguiente fragmento extraído de una obra de Pérez-Prendes es una buena síntesis de esta lógica:

18 Ibidem.

19 Cf. GaCto FernándeZ, E.: op. cit. (n. 3), pp. 49-51, apartado dedicado a la creación de derecho por albedrío.

20 Kelley, D. The buman measure. Social thought in the western tradition, Cambridge; Mass.Londres, 1990, p. x. 
«Este ordenamiento jurídico [el derecho consuetudinario castellano] del cual la comunidad es vivo testimonio, se fue fraguando muy lentamente en la práctica diaria y se transmitió de modo lento a través del paso de las sucesivas generaciones hasta que un día por la circunstancias que fuesen se hizo necesario exponerlo a los rectores de la comunidad y dejar constancia por escrito de esa manifestación... La fuerza viva del grupo fue dando forma, de padres a hijos, plasmando en sus memorias el criterio jurídico de la masa popular»21.

Con esta matriz teórica es lógico que aun estando ausente en la documentación la costumbre determine y hegemonice toda situación.

Del análisis documental, como hemos visto, no se deduce la presencia de derecho consuetudinario. Es esta concepción romántica de la costumbre la que hace posible ver una dominancia del derecho consuetudinario cuando aún no existe. En el nivel de los documentos esta situación cambia desde fines del siglo XII.

\section{UN EJERCICIO DE INTERPRETACIÓN EN CLAVE JURÍDICA: LA COSTUMBRE EN LOS FUEROS CASTELLANOS A PARTIR DEL SIGLO XII}

La situación hasta aquí analizada cambia radicalmente cuando nos situamos frente a los documentos del siglo XIII: la consuetudo aparece en los fueros como una constante. Veamos algunos ejemplos. Comencemos por el fuero de Medinaceli, en la provincia de Soria ${ }^{22}$ :

"Hec est carta quam fecit concilium de Medina celim super suis foris et consuetudinibus, cum beneplacito domini Alfonsi regi»23.

Se trata de una carta de fuero a través de la cual el nuevo rey confirma los fueros y las costumbres de la localidad. Al analizar el enunciado de este fuero nos damos cuenta de que es el propio concejo el que ha exigido el beneplácito del rey: la necesidad de establecer por escrito el ordenamiento jurídico de la región puede interpretarse como una forma de prevenir modificaciones posteriores por parte del príncipe ${ }^{24}$.

21 Perez-Prendes, J.M.: op. cit. (n. 15), p. 509.

22 Este fuero fue otorgado en 1180 , pero se conoce por una copia del siglo XIII.

23 MUÑOZ Y ROMERO, T.: op. cit. (n. 12), p. 435.

24 El historiador español J.A. Sardina Páramo considera que existe una relación directamente proporcional entre el aumento del poder público del monarca y la redacción de fueros. Un monarca fuerte aseguraba el mantenimiento de los privilegios frente al avance de otros sectores sociales. Ver SARDINA PÁRAMO, J.A.: El concepto de fuero. Un análisis filosófico de la experiencia jurídica, Santiago de Compostela, 1979, pp. 77-78. Es interesante también la noción de fuero que maneja el autor (ibidem, p. 78). El fuero se encuentra más cercano al pacto que a una norma soberana: «El rey cede, supuesta una fundamental actitud ética, en aquello que entiende no ser de su competencia», y logra el apoyo de la comunidad municipal; el concejo pide la aprobación del monarca para garantizar la perpetuidad de sus privilegios.

Hispania, LXIII/1, núm. 213 (2003) 9-28 
Otro ejemplo de esta presencia es la confirmación del fuero antiguo a Vallunquera que realiza Alfonso XI:

"Et ydeo uolo ut ab bodierno et deinceps omnis mala consuetudo de ipsa supradicta villa, scilicet, Valionquera sit abrasa et toto foro de Olmiellos ibi sedeat confirmato et non perdant ipsum forum nec filios nec neptos, set babeant eum omnis generacio eorum iure bereditario in perpetuum» 25 .

¿Qué designa la consuetudo en estos documentos? Por un lado, algunas referencias tienen un valor arcaizante, consuetudo designa las obligaciones feudales calificándolas como malas consuetudines.

Esta mala consuetudo señalada por el rey se refiere a las imposiciones feudales sobre las que él va a intervenir para limitarlas. En este caso, la concesión de un nuevo fuero deja sin efecto las obligaciones que esta comunidad tenía.

Por otro lado, vemos también en las redacciones forales de los siglos XIII y XIV una creciente tendencia a ubicar en el mismo nivel que la palabra consuetudo a las libertades o privilegios que posee una comunidad. Los historiadores que han analizado el fenómeno consuetudinario en las áreas de pervivencia del derecho escrito en el territorio francés, en la zona del Midi, también han encontrado a partir de este momento (siglos XIII y XIV) la utilización constante en los textos denominados consuetudinarios de los distintos términos (libertades, privilegios, franquezas, costumbres) en calidad de sinónimos. La costumbre se transforma en este período, según Poumarède, en un signo de libertad y en una marca de identidad ${ }^{26}$, se transforma en el modo particular en que los hombres de tal región o ciudad se comportan, lo cual los diferencia de cualquier otra comunidad. Esto se ve por ejemplo en el fuero de Valdemoro y Quintanilla de 1183:

"Dono et concedo vobis toto concilio de Valle de Moro et toti concilio de Quintanilla presentibus et futuris, tale forum et consuetudinem quale habet concilium de Castro Soriz in villa sua, ut pectetis eodem modo quomodo pectant homines de Castro Soriz»27.

No se trata de cualquier comportamiento. No sé está haciendo referencia simplemente a un hábito, sino a una práctica que en tanto privilegio o franquicia es del orden de lo jurídico. Al aprobar y autorizar una costumbre, el rey, en tanto lex animata ${ }^{28}$, la equipara a la ley - como fuente del derecho- y la intro-

25 Confirmación de Alfonso XI (1330) del Fuero de Vallunquera concedido por Alfonso VI en 1102; en GONZÁLEZ, J.: "Aportación de fueros castellano-leoneses» en AHDE 16 (1945) pp. 625654/629-631.

26 Poumarède, J.: «La coutume en pays de droit écrit» en RSJB 52 (1990) pp. 233-250/ 237.

27 MARTínez DíEZ, G.: Fueros locales en el territorio de la Provincia de Burgos, Burgos, 1982, p. 76. La misma noción encontramos por ejemplo en el Fuero de Treviño otorgado en el año 1250, ibidem, p. 103.

28 La idea del Príncipe como ley animada fue una construcción de los Doctores de Bolonia a partir del siglo XII. Parece provenir de la resignificación de la idea romana de que el emperador era 
duce en el ámbito del ius. Sin embargo, esa equiparación de la consuetudo a la ley tiene como contracara la subsunción de la primera a la segunda de forma tal que se concentre la capacidad generadora de derecho en las manos del príncipe.

¿Cómo podemos explicar esta presencia en Castilla desde el siglo XIII? Desde las interpretaciones que, como señalamos anteriormente, privilegian el carácter espontáneo del derecho consuetudinario, la pregunta misma es absurda. La costumbre siempre estuvo presente. Pero, como ya dijimos, uno de los objetivos centrales de este trabajo es dejar de lado esa matriz de pensamiento y reinstalar a la costumbre en el plano de lo jurídico. Por ende, la pregunta es pertinente porque la presencia del término costumbre nos indica que se ha producido un cambio en el interior del discurso jurídico. En este sentido, sostenemos que la aparición del término consuetudo a lo largo de los siglos XII y XIII está en estrecha relación con la influencia romanista en la región. En este punto establecemos una filiación directa con la tesis de Gouron, que afirma que la conciencia de la costumbre está siempre vinculada con la adopción en grados variables de la cultura jurídica asociada al derecho romano ${ }^{29}$. Si bien la recepción del derecho romano-canónico se dará plenamente en Castilla a partir del reinado de Alfonso X, es posible considerar desde fines del XII la existencia de expresiones técnicas y terminológicas del derecho boloñés ${ }^{30}$. Por otro lado, la influencia de la tradición jurídica de León permitió la reutilización de elementos romanos presentes en el Liber Iudiciorum.

La ley visigoda fue un mecanismo de introducción de elementos del derecho romano de forma temprana en la península. En aquellas regiones en donde el Liber se aplicó, León o Cataluña, apareció rápidamente un lenguaje que habilitaba la juridización de las prácticas reiteradas como usus, mos, consuetudo palabras que ya estaban presentes en el derecho visigodo- y que consagraba su carácter normativo ${ }^{31}$. El historiador Carlos Petit, que analiza la recurrencia de

el reservorio de las virtudes. A lo largo del siglo XIII existen documentos en los que se hace referencia al emperador como lex animata. La idea que entrañaba esta imagen era que el Príncipe era la ley viviente, a partir de la cual derivaban las leyes civiles. Está máxima se relacionaba con otra proveniente del derecho romano que sostenía que el emperador contenía todas las leyes in scrinio pectoris, en el escritorio de su pecho. Ver KANTOROWICZ, E.: Los dos cuerpos del rey. Un estudio de tealogía medieval, Madrid, 1985. Para un análisis más reciente del problema, Vallejo, J.: Ruda equidad, ley consumada. Concepción de la potestad normativa (1250-1350), Madrid, 1992.

29 Cf. Gouron, A.: "Aurore de la coutume», op. cit. (n. 11), p. 183: "Au fond, la leçon catalane comme la leçon italienne son claires: sans un minimum de culture juridique, sans le maintien, même ténu ou déformé, du souvenier des sources antiques, la prise de conscience de la coutume n'est guère possible».

30 Cf. Martínez Díez, G.: «Los comienzos de la recepción del derecho romano en España y en el Fuero Real» en Diritto comune e diritti locali nella storia dell'Europa. Atti del Convegno di Varena, Milán, 1980 , pp. 255-257.

31 Debido a estas características es posible comparar los datos de León con el caso catalán. A partir de las investigaciones de Iglesia Ferreirós en Cataluña vemos, por un lado, la precocidad de la utilización en los textos jurídicos de los términos traducibles por costumbre; pero también una

Hispania, LXIII/1, núm. 213 (2003) 9-28 
los términos mos y consuetudo en la leyes visigodas ${ }^{32}$, llega a la conclusión de que dichas palabras, lejos de hacer referencia a un «derecho germánico» latente, la mayoría de las veces remiten a una práctica romana. Para Petit, las explicaciones germanistas de los derechos hispánicos carecen de bases y fundamentos sólidos, al menos en sus presupuestos visigodos. En su rastreo de estos vocablos (consuetudo, mos, usus) encuentra que en ningún caso la referencia a la costumbre se explica por una continuidad germánica, sino que es la tradición romana tardía la base más probable de esas costumbres. Por lo tanto, la aparición de los términos consuetudo y mos en la legislación no necesariamente habla de la supervivencia de una derecho tradicional gótico que se desconoce. Habla por el contrario de supervivencias de prácticas romanas en zonas altamente romanizadas.

Esto nos permite sostener que en los territorios donde se mantuvo vigente la ley visigoda pervivieron a través de ésta elementos del derecho romano. Por lo tanto, es posible encontrar más tempranamente un lenguaje capaz de habilitar la juridización de las prácticas reiteradas como usus, mos, consuetudo y consagrar su carácter normativo.

Permítasenos una digreción para demostrar esta idea. La región de León es un buen ejemplo de esta pervivencia. Una rápida recorrida por los fueros leoneses nos muestra la influencia visigoda respecto de este tema. Consuetudo, mos y usus aparecen en numerosas oportunidades en la documentación. En dos ocasiones en el fuero de León (1017) aparece el término mos usado para remitir a la ley visigoda. En un caso, con relación al fonsado:

"Illi etiam qui soliti fuerunt ire in fossatum cum rege, cum comitibus, cum maiorinis, eant semper solito more» 33 .

En otro, prohibiendo la rapiña de los bienes eclesiásticos:

"Mandauimos adbuc ut nullus audeat aliquid rapere ab ecclesia; uerum si aliquid infra cimiterium per rapinam sumpserit, sacrilegium soluat, et quicquid inde abstulerit, ut rapinam reddat; si autem extra cimiterium iniuste abstulerit rem ecclesie, reddat eam et calumpniam cultoribus ipsius ecclesie more terre» 34 .

A lo largo del siglo XI es cada vez más frecuente la utilización del vocablo consuetudines. La presencia de esta palabra no debe llevarnos al error de considerar que hace referencia a la costumbre en el sentido que le atribuyó el derecho

\footnotetext{
tendencia conservadora que mantiene aún después de la elaboración del ius consuetudinarium los conceptos arcaizantes de consuetudines como poder de ban. Ver IGLESIA FERrEIRós, A.: «La creación del derecho en Cataluña» en $A H D E 47$ (1977) pp. 99-423; Gouron, A.: «Aurore de la coutume», op. cit. (n. 11), p. 183.

32 PeTIT, C. «Consuetudo y mos en la Lex Visigotorum» en RSJB 52 (1990) pp. 89-120.

33 RoDrígueZ, J.: Los fueros del reino de León, tomo II, Madrid, 1981, p. 19.

34 Ibidem, p. 17.
}

Hispania, LXIII/1, núm. 213 (2003) 9-28 
común o el derecho actual ${ }^{35}$. Aun cuando en la mayoría de los casos se haga constar su remotísima o inmemorial observancia, el término designa un derecho de origen público pero ejercido a título privado por los señores. Se refiere entonces a los deberes que los señores exigen a sus campesinos. Que se los denomine consuetudines indica que esas normas ya se aplican, o deberán usarse y aplicarse, y no que hayan nacido de la repetición continuada de unos mismos actos. Veamos como ejemplo qué señala al respecto el fuero dado por Alfonso VI a los pobladores de la villa de Sahagún:

«Ego Adefonsus Dei gratia totius Ispanie Imperator postquam sedi in trono paterno curam Ecclesiarum babere cepi, sed super omnes Ecclesiam Sanctorum Facundi et Primitivi quem antiquitus Dominis Sanctos vocitant amavi et per Domnum Benardum Abbatem in ordine Sancti Benedicti que est bona el religiosa declaravi atque ab omini iugo Regalis Fisci vel Ecclesiastice presure feci ingenuam. Dedi enim eam romane Ecclesie et Beati Oetri in libertate romana. Cumque adbuc cogitarem bonum quod facerem accesit ad me Abbas et rogavit quatinus darem foros ut esset bona villa in circuitu de Monasterio, quod devotus annui, et mox quod abas et monachi petebant concensi; ideo que monachorum do vobis bominibus populatoribus Sancti Facundi consuetudines et foros in quibus et serviatis Ecclesie et monasterii suprataxati»36.

Consuetudines designa las obligaciones que los hombres y pobladores de Sahagún tienen respecto de la abadía benedictina, impuestas a partir de la intervención del rey. Si seguimos el protocolo cabe decir que estas consuetudines son en sí mismas la reglamentación. La calificación de consuetudines, como las de usus, uso, o usatge -empleado frecuentemente en Cataluña-, indica que tales normas se usan o aplican, o habrán de usarse o practicarse; no que hayan nacido de la repetición continuada de unos mismos actos ${ }^{37}$.

¿Qué aspectos regulan estas consuetudines? En el caso del fuero recién citado, se trata de un conjunto de obediencias que ligan a los pobladores de la villa de Sahagún con la iglesia y el monasterio. A través de disposiciones que prohíben el uso de hornos y cocinas campesinas y establecen el pago al abad por utilizar «nullus babeat ibi furno vel patella, sed ubi fuerit invento frangitur, et det Abbati quinque solidos», podemos ver el avance del poder señorial sobre la comunidad ${ }^{38}$.

35 El derecho actual tanto como las elaboraciones de los romanistas sobre el Corpus Justiniano consideran a la costumbre como una fuente del derecho aunque subordinada a la ley.

36 RODRíGUEZ, J.: op. cit. (n. 33), pp. 35 y 37.

37 García Gallo, A.: Manual de historia del derecho español, tomo I, Madrid, 1977, p. 186.

38 Según Poumarède también en la zona del Midi francés aparece a partir del siglo XI el término consuetudines o usatica para denominar los cánones señoriales. Estas imposiciones son evidentemente la huella en los documentos del avance señorial sobre las comunidades y de la imposición del poder de ban. POUMARÈDE, J.: op. cit. (n. 26), p. 235.

Hispania, LXIII/1, núm. 213 (2003) 9-28 
Cada vez con mayor frecuencia en el siglo XII, la consuetudo adquiere otro valor: se territorializa. "Sed, sicut est consuetudo totis terre, propinqui hominis defuncti possideant bereditatem proximi sui si filium aut filiam non babuerints 39 .

Pluralidad de sentidos para la consuetudo (norma jurídica de tradición visigoda, obligaciones feudales, libertades o franquicias ${ }^{40}$ ), pero presencia al fin. Esta ambigüedad del término va a permanecer, pero se irá afianzando sobre todo la idea de la costumbre como derecho y como práctica jurídica de una determinada región.

En síntesis, el ejemplo de León, al igual que Cataluña, nos muestra que, por un lado, la utilización temprana en los textos jurídicos de los términos traducibles por costumbre va unida a la influencia romanista a través del Liber, y, por otro, una tendencia conservadora que mantiene aún después de la elaboración del ius consuetudinarium el concepto arcaizante de consuetudines como poder de ban.

A diferencia de León, Castilla no tuvo una temprana influencia del derecho romano. De allí que no encontremos hasta avanzado el siglo XII expresiones que remitan a la consuetudo. Cuando estos términos aparecen en Castilla este valor arcaizante de la costumbre presente en la región de León queda empañado bajo el influjo de la recepción romanista. La costumbre pasa a designar sobre todo una norma jurídica que es privilegio de una determinada comunidad:

«Sepan quantos este privilegio vieren como nos don Alfonso, por la gracia de Dios, rey de Castilla, de Toledo, de León, de Galicia (...) dámosles e otorgámsoles el fuero e privilegios e las franquezas que les dieron el rey Ferrnado, nuestro padre, e el rey don Alfonso, nuestro bisabuelo, e los otros reis, e los buenos usos e las buenas costumbres que entonces bavien, que lo bayan todo bien e conplidamente» ${ }^{41}$.

\section{DEFINIR, DIFERENCIAR, INSTITUIR: LA CONSUETUDO Y LA RECEPCIÓN ROMA- NISTA}

La adquisición de nuevos sentidos para la consuetudo, sentidos que fueran dejando atrás ese valor arcaizante de la misma, estuvo entrañablemente ligada

39 RodrúGuez, J.: op. cit. (n. 33), p. 53: Cláusula 2 del fuero que la Abadesa Teresa da a sus vasallos de San Pedro de las Dueñas en 1124.

40 Como ejemplos de este último caso podemos citar la carta que Doña María concede al concejo de Toro en 1283: Cláusula 1: «Dovos é otorgovos firmemente que ayades todos vuestros fueros, et vuestros privilegios, et usos et costumbres, et libertades, et franquezas, que habedes por privilegios et por cartas de los reyes que ante fueron et del Emperador et del Infante Don Sancho mi marido, et todos los otros que non babedes por privilegio ni por carta de que vos mas pagaredes». Cláusula 16: «Como contra todos los otros del mundo que a vos quisieren pasar en qual manera quier, contra vuestros fueros, et usos, et costumbres, et libertades, et franquezas, et privilegios, et cartas: et por esto sea firme et estable mandévos ende dar esta carta sellada con mi sello colgado"; en RODRíGUEZ FERNÁNDEZ, J.: Los fueros locales de la provincia de Zamora, Junta de Castilla y León, 1990, pp. 380-382.

41 Alfonso X confirma en 1272 a Sepúlveda el fuero, privilegios y franquicias otorgados por Fernando III; en SÁEZ, E.: op. cit. (n. 13), pp. 196-197. Otro caso representativo es el Privilegio de Don Alfonso el sabio a Alarcón devoloviéndole sus fueros, usos y costumbres, año 1303. 
a la recepción romanista. La recuperación del derecho romano y su aplicación al mundo medieval implicó una necesaria redefinición de la costumbre. La presencia en el Corpus Iuris de la consuetudo es en este sentido incuestionable. Tanto Juliano como Ulpiano, e incluso otros jurisconsultos romanos, hacían referencia a la costumbre en tanto dimensión ligada a la temporalidad: «inveterata consuetudo pro legge non inmerito custoditur»; o "diuturna consuetudo pro iure et legge». Planteaban así dos condiciones necesarias para la formación de la costumbre: el uso repetido por largo tiempo de una regla y la tácita «voluntas populi» ${ }^{42}$. No era necesario probar que los ciudadanos estaban de acuerdo con esa regla. Lo fundante era el sentimiento de conjunto y no el hecho en sí mismo.

Con estas características la costumbre se presentaba a los ojos de los juristas medievales como un concepto equívoco. En primer lugar, el criterio temporal era impreciso: no se establecía la cantidad de años necesarios para que una costumbre fuera inveterata, vetusta, etc. En segundo lugar, la causa de la costumbre remitía a la difusa categoría de la voluntas populi. En este punto había que definir no sólo la voluntad sino también a qué llamar pueblo. En tercer lugar, la relación entre consuetudo y lex, esencial para la estructuración del orden jurídico medieval, era contradictoria en el interior del Corpus Iuris. Por último, la costumbre hacía equilibrio entre el factum y el ius.

Frente a estas incertidumbres los juristas construyeron la categoría de ius consuetudinarium que no sólo incorporaba definitivamente la costumbre al ámbito del derecho sino que también resolvía en el proceso de su definición el conjunto de las imprecisiones que se presentaban en el derecho romano recuperado. Así pues, fueron los juristas medievales quienes enfrentados a estas dificultades elaboraron la teoría de la costumbre. La idea de consuetudo como conjunto de prácticas jurídicas de una región con valor de ius elaborada en el siglo XII por los doctores del derecho tuvo por objeto definir la "costumbre», trazando una distinción entre una dimensión que podría denominarse formal y otra que cabe designar como subjetiva. Esta discriminación asignó a la dimensión formal el papel rector en cuanto a la definición de la función jurídica de la costumbre y asoció la dimensión subjetiva con el conjunto de hábitos característicos de una sociedad de tipo tradicional.

La caracterización de la costumbre por parte de los civilistas a partir de la segunda mitad del XII se hará en función de cuatro criterios establecidos desde la doctrina: la naturaleza jurídica (ius), la factura antropológica (mos), la perspectiva temporal (diuturnitas) y la forma cultural (non scriptum). De este modo tiene origen el ius consuetudinarium. Lejos de ser estables, estos cuatro criterios trajeron aparejadas numerosas discusiones entre los juristas que intentaban establecer un punto firme para definir el derecho consuetudinario. Uno de los mayores problemas que enfrentaban los doctores del derecho era la estrecha

42 JUl. (D. 1, 3, 32, 1): tacitus consensus omnium; citado en DARemberG, C. y SAGLIO, M.E.: Dictionnaire des antiquités grecques et romaines, París, 1918, p. 2001.

Hispania, LXIII/1, núm. 213 (2003) 9-28 
relación que en el mundo romano guardaba la consuetudo con la tradición, ligadura que sumergía a la costumbre en un mundo subjetivo en el que la recreación y la renovación no tenían una pauta fija, donde el sentido era fundamentalmente precario ${ }^{43}$. Para transformar la consuetudo en derecho era imprescindible separar ambos términos. Tres operaciones en el corazón mismo del campo jurídico tuvieron por finalidad esta distinción: la elaboración de una definición técnica de consuetudo en donde no apareciera el criterio de la oralidad ${ }^{44}$; la separación de la costumbre del orden factual ${ }^{45}$; la determinación de una temporalidad definida ${ }^{46}$. Juristas franceses e italianos discutieron a lo largo de la Edad Media en torno a estos criterios. Lo cierto es que el ius consuetudinarium que no existía en el corpus romano recuperado nació como resultado de este proceso de conceptualización.

Una vez instituido el ius consuetudinarium la tarea se orientó hacia la precisión de los alcances que tendría la consuetudo respecto de la ley ${ }^{47}$, cuestión frente a la cual los juristas se encontraban con un problema inicial. La lectura diacrónica que hacían de los textos justinianos los llevó a tratar de conciliar dos textos del Corpus aparentemente contradictorios. Se trataba, por un lado, de un pasaje del jurista clásico Juliano en el Digesto en el que los romanistas veían la posibilidad de admitir que la ley podía ser abrogada por tacito consensu omnium per desuetudinem ${ }^{48}, \mathrm{y}$,

43 El derecho romano había hablado de consuetudine inveretata $(D .1,3,32)$, diuturna (ibidem, 33), per annos plurimos observata (ibidem, 35), longe (C. 8, 52), pero no precisaba el tiempo exacto (CALASSO, F.: Medioevo del diritto, Milán, 1954, p. 205). La tradición romana había dejado una importante laguna donde debía establecer el lapso de tiempo para considerar a una costumbre longa, longeva, inveterata, diuturna. Con este criterio la temporalidad era abiertamente subjetiva; una práctica tenía valor consuetudinario cuando no era posible remontarse a su origen porque la memoria colectiva no alcanzaba a rastrearlo. Su régimen de temporalidad era estar «fuera del tiempo». Pero este criterio atentaba contra la formalización de la consuetudo. Los glosadores posteriores le fijaron una temporalidad. Bassianus, por ejemplo, estableció una tabla de equivalencias en la consideración de la antigüedad de la costumbre. Consideró longa consuetudo aquella que estaba vigente durante diez o veinte años; más antigua, longissima, a la de treinta o cuarenta años; longeva la de cuarenta; y vetusta aquella de la cual se había perdido la memoria de su origen (CORTESE, E.: La norma giuridica. Spuntici teorici nel diritto comune classico, tomo II, Varese, 1962, p. 143)

44 Si el primer criterio que distinguía a la consuetudo era el tratarse de un derecho no escrito, a partir del siglo XII esta idea fue cuestionada. Jacques de Revigny planteó que la «scriptura non est substantis legis" (MAYALI, L.: op. cit. (n. 10), p. 19). Si la escritura no es sustancia de la ley, la oralidad no es la marca de la costumbre. Fue necesario elaborar un método más analítico para distinguir ley de consuetudo. Así, con el olvido de su oralidad, la costumbre perdía su apego simbólico a una cultura tradicional donde la escritura no tenía un rol predominante.

4s El trabajo de los glosadores consistió en establecer diferencias entre mos, usus y consuetudo. Revigny consideraba que ius es consuetudo y factum es usus, mos. De esta manera, la costumbre vio reconocida su esencia jurídica, a diferencia de usus y mos, indispensables para su formación pero emplazados en un plano puramente factual.

46 Para un análisis acabado de éstas tres operaciones, MAYALI, L.: op. cit. (n. 10).

$47 \mathrm{Al}$ respecto, ver CORTESE, E.: Il renascimento giuridico medievale, Roma, 1996, pp. 67-69.

48 D. 1, 3, 32, 1: «inveterata consuetudo pro lege non inmeritio custoditur... leges tacito consensu omnium por desuetudinem abrogentur»; citado por GoURON, A.: «Coutume contre loi chez les premiers 
por otro lado, de una constitución de Constantino donde se refutaba la validez de la costumbre a punto tal de considerar imposible que la consuetudo pudiera vencer rationem aut legem. Durante el período que va del siglo XII al XV se buscó salvar esta contradicción y formalizar la consuetudo. Valga de ejemplo de estos esfuerzos la interpretación de Bulgaro, muy ansioso por conciliar ambos fragmentos. Según el jurista, el fragmento de Juliano sostenía la posibilidad de que una ley fuera abrogada por el desuso, ya que consideraba la hipótesis de una costumbre introducida con el conocimiento de la existencia de una ley contraria, en tanto que Constantino aludía a una costumbre ignorante de la coyuntura $^{49}$. Esta interpretación fue rápidamente criticada por el resto de los glosadores. Con posterioridad se consideró que el pasaje del Digesto 1, 3, 32, no correspondía a Juliano sino que habría sido una adición posterior ${ }^{50}$.

Las discusiones que se desarrollaban entre los juristas de Bolonia y Orleans, anclaron también en el mundo hispánico cerca de la corte de los reyes. Cuando comenzó a estudiarse en Bolonia el nuevo derecho de la iglesia, es decir, el Decreto de Graciano, muchos clérigos españoles viajaron a aprender el derecho romano en dicha universidad. Su regreso a Castilla supuso la formación de un grupo de juristas con un bagaje técnico y una rigurosa formación doctrinal hasta ese momento desconocidos en la península. Como consecuencia de esta renovación intelectual se fundaron a principios del siglo XIII los Estudios generales de $\mathrm{Pa}$ lencia y Valladolid, donde se estudiaba tanto el derecho romano como el canóni$\mathrm{co}$, hecho que condujo a un aumento significativo del número de juristas.

El monarca que llevará adelante una política agresiva en materia jurídica incorporando los nuevos elementos del derecho romano y del derecho canónico será Alfonso X. Los historiadores que se han dedicado al análisis de la obra legislativa del rey $\mathrm{Sabio}^{51}$ consideran que la producción jurídica del rey tenía un triple objetivo: en primer lugar, la reivindicación de la creación del derecho por parte del monarca; en segundo lugar, la unificación jurídica de sus reinos; por último, lograr

glossateurs» en A. Gouron y A. Rigaudière (eds.), Renaissance du pouvoir législatif et genèse de l'État, Montpellier, 1988, pp. 117-130/118.

49 CORTESE, E.: La norma giuridica. Spuntici teorici nel diritto comune classico, op. cit., p. 110.

50 Thomas, J.A.C.: «Custom and Roman law» Revue d'Histoire du Droit (Dordrecht) 31 (1963) pp. 39-53.

51 García Gallo, A.: «El "Libro de las Leyes" de Alfonso el Sabio. Del Espéculo a las Partidas» en $A H D E$ 21-22 (1951-52) pp. 352-528; «Nuevas observaciones sobre la obra jurídica de Alfonso $\mathrm{X}$ » en $A H D E 46$ (1976) pp. 609-670; «La problemática de la obra legislativa de Alfonso X» en Boletín del Colegio de Abogados de Madrid 5 (1984) pp. 8-19; MACDONALD, R.A.: "Problemas políticos en el derecho alfonsino" en $A H D E 54$ (1984) pp. 12-53; CRADDOCK, J.: "La nota cronológica inserta en el prólogo de las Siete Partidas. Edición y comentario» en Al Andalus 39 (1974) pp. 363 390; "La cronología de las obras legislativas de Alfonso X el Sabio» en $A H D E 51$ (1981) pp. 365418; Iglesia FerReirós, A.: «Alfonso X el Sabio y su obra legislativa. Algunas reflexiones» en $A H D E 50$ (1980) pp. 531-561; "Cuestiones alfonsinas» en $A H D E 55$ (1985) pp. 95-149; «La labor legislativa de Alfonso X el Sabion en Actas del Simposio Internacional del Instituto de Derecho Común: España y Europa, un pasado jurídico común, Murcia, 1986, pp. 275-599.

Hispania, LXIII/1, núm. 213 (2003) 9-28 
una renovación jurídica del reino en todos los niveles ${ }^{52}$. En función de estos fines, el derecho romano-canónico fue su referente fundamental, especialmente en relación con el objetivo de considerar al monarca como creador del derecho.

Es a raíz de este aspecto que surgirá la necesidad de dar una definición acabada del término costumbre. Establecer un sentido específico para la costumbre era garantía del éxito de la operación de subsunción de cualquier otra forma de producción de derecho a la capacidad normativa del rey. Es en estos intentos de definición donde vemos que se retoman en la obra jurídica de $\mathrm{Al}$ fonso $\mathrm{X}$ los problemas planteados en las universidades de Italia o en París: las dificultades para diferenciar la costumbre del uso o del fuero; los intentos de fijarla temporalmente; la subordinación de la costumbre a la ley que emana del monarca. El texto de la Primera Partida, por lo menos en las versiones que han incluido un título sobre la costumbre ${ }^{53}$, nos ofrece un amplio panorama sobre estos tres temas ${ }^{54}$. Para terminar, las Partidas ofrecen las condiciones de existencia de la costumbre que tienen como fuente tanto a los romanistas más reconocidos como al derecho canónico: en primer lugar, la costumbre debe ser resultado de la voluntas populi; en segundo lugar, debe ser confirmada por la jurisprudencia ( Si en estos tiempos fueron dados dos juicios por ella»); en tercer lugar, la costumbre debe ser con razón y no contra el derecho natural o contra el de la tierra; en cuarto lugar, un requisito que añade particularmente el código alfonsino: debe existir el consentimiento del señor de la tierra; por último, la persistencia por un lapso de tiempo de diez o veinte años ${ }^{55}$.

52 MARTínez LIORENTE, F.: Régimen jurídico de la Extremadura castellana medieval, Valladolid, 1990, p. 238.

${ }_{53}$ Existen actualmente varias versiones de la Primera Partida y no todas contienen un título dedicado a la costumbre. Seguimos en este punto al análisis realizado por MORIN, A. y CUCCHI, S.: «El tratamiento de la costumbre en la Primera Partida de Alfonso El Sabio» en Anales de Historia Antigua y Medieval (Buenos Aires) 30 (1997) pp. 107-121. Dicho trabajo se centra en las siguientes ediciones: Díaz De MONTAlvo, A.: Siete Partidas, ADMYTE (Archivo Digital de Manuscritos y Textos Españoles), vol. 1, Madrid, Biblioteca Nacional / Micronet, 1922 (transcripción y facsímil de la edición sevillana de 1491); LóPEZ, G.: Las Siete Partidas, Salamanca, A. de Portonaris (ed.), 1555 (reproducción anastástica de la editorial Boletín Oficial del Estado, 1982); Real Academia de la Historia, Las Siete Partidas del rey don Alfonso el Sabio, cotejadas con varios códices antiguos, 3 tomos, Madrid, Imprenta Real, 1807. La versión del Manuscrito Británico editada por Arias Bonet, por el contrario, no contiene ningún título que haga referencia a la costumbre.

54 Para un análisis en profundidad de este problema, MORIN, A. y CUCCHI, S.: op. cit. (n. 53).

ss SÁNCHeZ DE LA VeGA, G.: "Costumbre a partir de las Partidas» en RSJB 52 (1990) pp. 151-169/ 155-156. Estas condiciones quedan claramente expuestas en el Título II, Ley 5 de la edición de Montalvo: «E tal pueblo com (m) o este o la mayor $p(a)$ rtida del si vsara(n) .x. o xx.(.) años fazer algu(n) a cosa com $(m)$ o en manera d(e) costu(n)bre sabie(n) dolo el señor dela tierra Eno la co(n)tradizie(n)do puedela fazer $\mathcal{E}$ deue ser tenida $\mathcal{E}$ guardad por costu(n)bre: si eneste tie(n)po fuere(n) dados dos iuyzios por ella :esto mismo seria $q(u) a$ 'ndo co(n)tra tal costu(n)bre enel tie(n)po sobre dicho alguno porfiase su dema(n)da o su $q(u e)$ rella o dixiese que no era costu(n)bre el iudgador a $(n)$ te $q(u) i$ ' en acasçiese tal co(n)tie $(n)$ da no reçibiese tales querellas co(m)o estas o iudgase $q(u e)$ era costu(n)bre en todo refusa $(n)$ do las razones de aq(ue)llos $q(u e) l l o s q(u e)$ la $q(u e)$ ria $(n)$ co(n)tradezir».

Hispania, LXIII/1, núm. 213 (2003) 9-28 
En definitiva, y a esto queríamos llegar, en el siglo XIII se fijan, tomando como referencia las glosas y comentarios al Corpus Iuris, los criterios de existencia de la costumbre. Es el momento, por lo tanto, en que se instituye la regla jurídica que crea a la costumbre como derecho. No hay nada de natural y popular en la costumbre en tanto sus pautas han sido fijadas arbitrariamente desde un discurso doctrinal.

La difusión social que adquieren los conceptos del derecho docto permitió el uso, en la práctica jurídica concreta, de los términos que la Glosa romanista habilitaba. Y es por esta razón que durante el siglo XIII encontramos que la utilización de la consuetudo como práctica jurídica de una región se hace verdaderamente muy frecuente en los textos jurídicos forales. El derecho consuetudinario existe porque hay una regla en el interior del discurso jurídico que otorga a ciertas prácticas la significación de derecho.

\section{REFLEXIONES FINALES}

A lo largo de nuestra investigación hemos intentado, por un lado, hacer una crítica al romanticismo presente en las interpretaciones de la costumbre, y, por otro, demostrar que la influencia romanista es fundamental para la existencia de la consuetudo. El derecho consuetudinario, pues, comenzó a existir en los fueros cuando se produjo la invención del concepto y no a partir de la simple constatación de una realidad exterior al discurso. El derecho romano canónico construyó la regla jurídica que instituyó las pautas para que un tipo de regularidad deviniera norma. Fue necesaria la existencia del concepto para que el fuero pudiera instituir mediante la nominación a un conjunto de prácticas sociales como prácticas jurídicas normativas.

Dos problemas se derivan de esta cuestión, problemas que difícilmente serán resueltos de forma definitiva en esta conclusión pero que merecen una reflexión aunque sea provisoria. En primer lugar, equé entendemos por nominación? En segundo lugar, ¿qué estatuto jurídico tienen esas prácticas nominadas bajo la voz consuetudo?

La nominación es un acto creador. Nominar en el interior de un discurso no es simplemente darle un nombre a algo que preexiste de forma anónima, es, ante todo, crear objetos, instituir una presencia. El nombre no es un reflejo pasivo de una esencia contenida en la cosa sino una intervención que ordena, da sentido, y por lo tanto transforma al objeto nominado. La nominación «representa» pero en el sentido planteado por Marin, es decir, como operación que instituye un nuevo lugar ${ }^{56}$.

56 Para L. Marin la representación debe ser definida como presentación de una ausencia y no como traspaso de esencias: "Au lieu de la représentation donc, il est un absent, dans le temps ou l'espace ou plutôt un autre, et une substitution s'opère d'un autre, à sa place». (MARIN, L.: Des

Hispania, LXIII/1, núm. 213 (2003) 9-28 
¿Qué es entonces ese «algo» sobre el cual se monta la nominación? ¿Qué estatuto tiene lo que queda conceptualizado bajo el término consuetudo? Como vimos en el análisis documental, en los fueros existen formas de remitir a un saber-hacer en estado práctico que se liga directamente con una dimensión temporal. El ejemplo más significativo aparece en el Fuero Latino de Sepúlveda en donde esta dimensión temporal se hace presente a través de la frase: «quod habuit in tempore auoli mei». Este saber-hacer se encontraba estrechamente ligado a la inmemorialidad pues no había un parámetro externo a la memoria que fijara cuál era esa antigüedad. Existen, por ende, regularidades que el texto del fuero contiene. ¿Qué relación guardan estas regularidades ligadas a lo inmemorial con el concepto de consuetudo? La mejor forma de contestar a esta pregunta es retomar la idea de nominación. Si como dijimos, dar un nombre es crear, llamar consuetudo a unas prácticas no es reflejar bajo ese concepto lo que son en esencia sino todo lo contrario: significa transformarlas en otra cosa, atribuirles un sentido ligado a ese nombre. La consuetudo «representa» porque ocupa el lugar del ausente, es decir, el lugar de las prácticas regulares ligadas a la inmemorialidad. La labor de los juristas fue precisamente la de construir un concepto que neutralizara el carácter subjetivo de esas prácticas. El acto de creación del concepto ius consuetudinarium no sólo instituiría el nombre sino también las prácticas que desde entonces quedarían nominadas bajo dicho nombre.

pouvoirs de l'image. Gloses, París, 1993, p. 11). Representar es presentar una ausencia, tomar su lugar. Hay algo de artificio en la representación: para representar es necesario que exista una ausencia; o invirtiendo la fórmula representar es crear una ausencia para instituir un nuevo lugar. En estos términos podríamos decir que el "derecho consuetudinario representa una voluntad popular» pero no porque el derecho derive de ella sino porque la voluntad popular se encuentra ausente en tanto el derecho consuetudinario ha devenido su representante. 